\title{
Mobile Education: Pedagogy, Technology and Collaboration
}

\section{Robert Kalwinsky, Middle Tennessee State University, USA}

\section{Introduction}

Those of us who are educators strive to find and create landscapes for inquiry within and beyond the classroom, and for many, new technologies and interdisciplinary efforts offer an opportunity for these strivings. At the surface, our disciplines contain information and perspectives; these inform and enrich each other, and with active learning, shared world experience, observation, collaboration, and reflection, they become the knowledge and culture of critical thought.

Each innovation in technology brings a new opportunity to education. Some, like the Internet, are proven and widely used; others, like educational software, have had less success. Still others are new and just beginning to see their first use.

In this article, experiences and perspectives are presented on the use of relatively new technologies, wireless, specifically 802.11 (Wi-Fi) and 3G enabled devices, and a framework of collaboration as tools for instruction and learning in digital video media classes. 


\section{Overview}

During the fall semesters of 2003/4, the spring semester of 2006 and the fall semester of 2010, the author taught several courses in digital media and videography, courses offered in Middle Tennessee State University's Department of Electronic Media Communication. For these offerings, he developed and implemented a new course format, where students could create digital productions by applying learned theory, with a substantial wireless technology component. Three factors motivated the project: a strong belief, founded in the theories of education, communication, and cultural studies, that a focus on wireless and mobile devices would benefit the learning process in several important ways; the ability to incorporate sufficient time to study and learn the technology within the existing goals of the course in order to prepare students for the intensive use of a technology with which they had no prior experience; and the suitability of the project as a whole to institutional resources, experiential opportunities, and departmental priorities. The focus on collaboration permitted comparison of outcomes with courses in basic television production, also taught by the author, and that more often involve cooperation rather than collaboration ${ }^{1}$.

The projects succeeded on many levels, although adjustments were made that resulted in improvements, as noted in the discussion section.

\section{Theoretical Frame}

In Western Culture, the confinement of the body for learning began in the Middle Ages (Foucault, 1997). The text forms of the era, rare and expensive illuminated manuscripts, were chained to desks to prevent theft. Although technological advances from the printing press and xerography, and societal changes, including the democratization of education, have improved the culture of learning, practices related to confinement and surveillance still permeate social processes and are visible in the modern classroom, which is a passive and strictly guarded institutional form based largely on linear, one-

\footnotetext{
${ }^{1}$ Cooperation is accomplished by the division of labor among participants, as an activity where each person is responsible for a portion of the problem solving..." while collaborative learning involves the "... mutual engagement of participants in a coordinated effort to solve the problem together" 
thing-at-a-time cognitive approaches delivered by an all-observing teacher (Nunberg and Eco, 1996). Educational theory and practice strongly support breaking free of this culture and promoting collaborative and experiential learning environments, to supplement the linear with multifocal modes. Conditions conducive to deep learning ${ }^{2}$ can be fostered by encouraging increased student-faculty contact and cooperation among students (Chickering and Gamson, 1987; Freire, 1993); supplying opportunities for cognitive apprenticeships (Bransford, Brown and Cocking, 2000); and emphasizing higher-order thinking involving real-world tasks (Chickering and Gamson, 1987; Oblinger, D. G., \& Oblinger, 2005). In this framework learning is not a matter of passively collecting concepts, but of constructing conceptual forms that integrate and link learning with one's entire life experience (Kirschner, P. A., Martens, R. L., \& Strijbos, J. W., 2004).

For 'deep learning', students should be able to apply and generalize what they have learned. And collaborative, convergence learning is the gold standard for developing the deep learning and critical thinking skills that are the focus of many second generation new-media e-learning environments: in a University of Minnesota analysis of over 160 studies, collaborative learning was consistently superior to competitive or individual learning, in terms of achievement and higher-level thinking skills (Johnson, Johnson and Stanne, 2000).

Experiential learning in higher education generally follows one of two models: group experiential learning or individual experiential learning. Each has advantages and disadvantages. For example, group experience benefits from the potential for collaboration, but it risks intruding on the environment and is not aligned with our cultural norms. Individual experiential learning provides a more tailored experience, but with less potential for collaborative or didactic adjuncts. Wireless and mobile technologies have the potential to support a hybrid experience with the advantages of group and individual experiences but none of the disadvantages. They encourage

\footnotetext{
${ }^{2}$ Deep learning: learning that promotes the development of conditionalized knowledge and metacognition through communities of inquiry.
} 
reasoned approaches that are relatively autonomous, yet also incorporate group dynamics, while offering the buffer of quick connection to the professor in case of problems. They foster the shift from individual to group cultural forms. And by definition, wireless technology allows us to communicate as a group without restricting our physical location and by offering temporal flexibility. A collaborative group of learners and their new media learning tools constitute a distributed system that self-organizes in a different way than a group of learners given individual, specific tasks. Among other aspects, putting students into groups "... compels them to explain their thoughts to one another with several advantages: on the one hand, verbalization requires reflection (upon one's own thoughts as well as upon what the others are saying) and, on the other, students tend to listen more openly and with more interest to their fellow students than to the teacher (Ernst von Glasersfeld, 2001).”

\section{Best Practices and Cultural Modification}

Concepts from cultural studies also informed the approach. Best practices were an integral component in designing and implementing the collaborative process, but with some modifications. Best practices are to a certain extent monolithic, and situations require variations based on cultural norms. Based on research and analysis ranging from Raymond Williams (1983) to Edward T. Hall (1997), cultural studies in part leads researchers to recognize that what is seemingly innate is actually a complex amalgam of social, political and psychological forces that are culturally framed.

For example, best practices seek to encourage social learning, but it would be a mistake simply to begin with collaborative efforts. Rheingold (2003) talks of the use of wireless devices among Japanese and Finnish subpopulations, and notes a) that both are populations used to living in very close proximity to other members of their respective communities and b) that they have embraced PDAs to such an extent specific forms have evolved that are part of day to day existence. Japanese clothes are designed to hold PDAs, and these electronic devices, along with cell phones, are even being used for reading novels and other detailed, lengthy literary forms (Kageyama, 2005). Finns use 
the term 'kanni' to talk of the devices, a word that essentially means 'hand'; they are that integral to their communication forms. In the United States, PDAs took more time to be vitally situated. From a cultural studies perspective, it makes sense that these components will not be as quickly accepted here: ours is not a sociocentric culture. We often live in suburban dwellings, largely separated from contact with others, and our cultural grounding is in the individual ${ }^{3}$. What obtains elsewhere may suggest best practices, but an understanding of cultures must inform our implementation. Regarding wireless in the classroom, we discovered that we should progressively introduce sociocentric forms that create comfort with what is essentially a group process, given our culture where the individual is more sanctioned and autonomy given ascendance. This refers less to the technologies than to collaborative efforts. Our students' needs require the gradual introduction of these forms, that they may comfortably accommodate a new paradigm for learning.

On another level, much has been made of the impact convergence and mobile devices are having on student interactions and cognitive processes. Referred to as the 'demotic turn,' it is more than the popularization of activity (e.g., YouTube), it is the move away from linear and didactic forms to rhetorical, image-based interactions and yet still contain significant market insertion (Miller, 2009). The courses were designed to activate these sorts of interactions and questionings.

In summary, the author used technology in collaboration with elements of educational and cultural theory to enhance learning and implementation of concepts in a digital environment. Technology has often promised to benefit education, and it often has. Telephone, e-mail, photography, and xerography are a few of the technologies that partially support collaborative or experiential learning. The use of wireless technology was an attractive prospect: it had the potential to support strong collaborative and

\footnotetext{
${ }^{3}$ Uses will also vary structurally: while the Finns use PDAs to literally communicate with their buildings, given their appreciation and use of architecture and their concomitant comfort with it, in the U.S. we do not have that deep affinity for physical structures. Our only truly national film genre, film noir, is rife with examples of characters being dwarfed by the buildings that surround them: our legacy is the individual in the open spaces. Thus we concentrate on communication between individuals, which is not necessarily the sole use of this form in other countries.
} 
experiential activities and foster deep learning, while simultaneously including important aspects of classroom pedagogy.

\section{Methodology}

In collecting and analyzing data, the theoretical groundings indicated a qualitative approach that would be dialectic and dialogic. A constructivist ${ }^{4}$ ethnographic approach was ultilized, in effect focusing on interaction and dialectic interchange. My role in this participation was that of instructor, although the form of teaching meant that the instructor became decentered as time evolved. The project was approved by the Institutional Review Board and the students gave informed consent. Even though the students were aware this was research, rather than highlight the observational data collection by taking notes during class and thus directly affecting student perceptions and actions, I decided to make notes after the interactions to ensure a more natural environment. These notes, augmented with student journal entries, a post-final questionairre and a quantitative analysis of test scores, provided a method of triangulation. Analysis involved analytical induction of notes and journal entries as well as discourse analysis to glean experiential concerns. I tried to bracket my observations to attempt some degree of unbiased analysis as well as to support the constructivist approach of collective generation of meaning. As facilitator of the inquiry process, I was quite aware of the need for equal consideration among participants. Finally, as part of the constructivist method, participants were allowed to read and comment upon results, which were fed back into the review process. The findings consisted of information from four classes, for a total of 119 students.

\section{Implementation}

For the first six weeks, the author proceeded to establish the basics in linear, didactic fashion. For example, in the survey class, key classroom topics ranged from Tufte to transistors, students gained practice with software applications like FinalCut Pro, Photoshop and DVD Studio Pro, and through readings and discussion we grappled with

\footnotetext{
${ }^{4}$ Constructivists believe knowledge and truth are the result of perspective and thus are created rather than discovered by the mind. 
Negroponte's views concerning interface design and social change. The students used mobile devices throughout the course. Even when students were just learning to use them, the devices were valuable educational tools. For example, students used wireless devices to look up unfamiliar concepts during class: this solidified the students' baseline knowledge, gave them assurance with key concepts, and simultaneously provided familiarity with the new technology. Wireless technology also tapped into just-in-time Internet information, where ideas can be rapidly situated and explored. Students delved into topics of interest in real time, adding depth to the pedagogical efforts in the course. Digital media in general, and the Internet in particular, creates a significantly different context for student-faculty communication than the traditional classroom, one with significantly less power differential (McCain, Maxwell, 2003). There were many opportunities for the students to be the teachers (e.g., television production students teaching Final Cut Pro, photography students teaching PhotoShop, etc.). Wireless use for rapid information retrieval in the classroom also brought to life an important issue related to electronic media: the surfeit of information and questions of validity. This informed many small group conversations and research, and fostered critical thinking skills.

The very beginning was a period that required transition. As mentioned, teaching at first was largely didactic. While many educators begin with a dialogic approach, often derived from the work of Freire, this may not be as useful during very early forms of learning, where cognitive baselines need establishment before the move toward autonomy. Further, even seemingly pure dialectic approaches have counterforces:

[Freire's] approach is still curriculum-based and entails transforming settings into a particular type of pedagogical space. This can rather work against the notion of dialogue (in that curriculum implies a predefined set of concerns and activities). ... the rhetoric which announced the importance of dialogue, engagement, and equality, and denounced silence, massification and oppression, did not match in practice the subliminal messages and modes of a Banking System of education. Albeit benign, Freire's approach differs only in degree, but not in kind, from the system which he so eloquently criticizes. (Taylor 1993: 148) 
As technical skills improved, a more Socratic approach developed, leading to full use of the 802.11b and PDAs within the context of an active, engaged learner using critical thinking and self-directed learning strategies. The work group paradigm, and later the formation of virtual teams, began the process of decentering the instructor. Studentfaculty contact was fostered initially, and throughout the process most students remained comfortable in turning to the faculty for needed assistance.

The first half of the course fulfilled several objectives: at the course midpoint, students had a good basic understanding of electronic and digital media, students were very comfortable using technology, and a group work paradigm was firmly in place.

Mobile devices and collaborative efforts contributed significantly to the realization of these objectives. The development of groups required a careful, step-wise progression, and mobile devices assisted with this transformation, since it ensured the development of good interpersonal and group skills in its utilization. Given our cultural constraints, the difficulty in sustaining heterogeneous, short-lived groups seemed daunting, and wireless was also significant in sustaining the groups. Another means of fostering collaborative work was an emphasis on critical thinking. As an inductive process it leads to a focus on wider concerns, leading from the individual to the whole. Again, wireless projects are well-suited for this dynamic; they require conceptualizing beyond an immediate task to larger, interactive responsibilities and problem solving situations. Journal entries provided the evidence that these concepts were realized: during the didactic phase of the course, entries were cursory and formal; by the time wireless implementation was underway, almost all entries captured thought processes and explorations of ideas not evident in the early entries. These later entries were fluid accounts of explorations and they sometimes contained mistakes as the students grappled with the terminology in new contexts: 
"We tried to capture audio but someone (ok, me) forgot the headphones and so then we had to rely on the meters which really is the best way. And then we forgot that these were digital equipment, like we weren't focused on that with all the activity and we weren't used to digital equipment. It's important to know because the audio pot gain is pretty different. I'm surprised I finally remembered with all that tension. By the time the interview started the stress was terrible and I began to control what people said. The questions were definitely not open-ended at all. So I stopped and took a breath and began again...."

Later efforts also benefited from wireless as well as other techniques. For example, in terms of time on task, most projects required significant scheduling, interaction with important contacts, and production deadlines that necessitated effective time management and production efficiency; mobile devices helped provide that and added some flexibility to scheduling. Group formations also ensured that any laggards were quickly confronted and pressured to become task oriented. To develop skills in articulating, reflecting, and exploring, students were required to keep a journal. The effects of this transformation took interesting form in the journal entries. Terminology went from rigid and impersonal ("wireless has the potential to effect changes;" "the form of communication strategy that complements this model relates to...") to personal, collaborative forms ("we discussed this issue and our belief is this technology has to revolutionize the use of TV news gathering..." and "attitudes changed drastically during the period of production as we..."). The students evidenced manipulation of concepts and ownership of knowledge acquisition in a personal fashion.

Along the way, accidents were encouraged, and people were deliberately reassigned to different positions to foster meaningful growth and exploration of talents. These all interwove into the best practices of active learning and fostering respect for diverse abilities as well as diverse ways of learning. 


\section{Projects}

Following are four of the projects completed:

Project 1. Mock Newscast.

In this project, students created a mock newscast. This was a class primarily composed of Mass Communication Production and some Journalism students. Goals were for students to understand the technical requirements of broadcast news and to confront the difficult question of objectivity in reporting.

Using $802.11 \mathrm{~b}$ and $3 \mathrm{G}$ networks allowed students to provide alternate commentaries within the news program. Wireless laptops, PDAs, and fitted cameras allowed synchronous coverage of the news from several locations. The feeds were sent back to the classroom and linked to a simulated broadcast on a computer station. The experience of negotiating spatial and temporal concepts in a real life situation was an epiphany for many students: they saw first-hand how perspectives differ across time and space ${ }^{5}$. For example, wireless technology enabled something difficult to include in standard news broadcasts: multiple points of view, through interactive thumbnail interviews of people with different perspectives and different spatio-temporal relationships to the news event. They could explore the subjective nature of accounting in a way that would be technically cumbersome if not impossible with standard equipment. Group formations emanating from wireless use also informed the different structure of decision-making, which was less centralized and less dominated by a top-down approach, as delineated below.

Project 2. Mapping the wireless campus: war chalk and web pages.

The next project had effects seemingly related less to the use of wireless than to to group dynamics and communication, but it is arguable that without the far-reaching effect of wireless (from production to transmission) and the related interest in pushing boundaries for a new technology, the specific interactions delineated would not have transpired. The goal of this project was to map wireless access at MTSU in two ways: as a standard map

\footnotetext{
${ }^{5}$ These perspectives may have been realizable with standard equipment, but not as readily (e.g., how often do you observe this sort of treatment, if ever?) and the limitations of the cables and the bulky equipment of standard news interviews also place constraints both physically and intellectually on how the information is acquired and exhibited.
} 
delivered on a website (created with Dreamweaver and hand-coding), and directly at the access locations, with chalk markings. The term "war chalk" is an allusion to the Depression era practice of placing chalk icons in front of houses to provide information about the homeowners: that they were likely to offer free food, exchange food for work, might be hostile to strangers, and so on. Similar marks were already used in Nashville to characterize wireless access points and hotspots near businesses.

Web development and coding were accomplished readily - the students who joined this group tended to have sophisticated skills in coding, if not design. Applying ideas from experts such as Tufte to design was one collaborative effort that had interesting results, and in terms of production was the area that offered some of the greatest creative development. On a practical level, students expected this project to be straightforward and mechanical, and they were surprised at the cultural clashes and varied negotiations that arose. Conversations took place with the campus Macintosh users group, the Instructional Technology department, and administrators; compromises had to be made, particularly regarding war chalk. Among other valuable experiences, students came to understand the need for sound, professional and diplomatic communications when dealing with administrators and others in positions of power. Interactions also provided a critical forum for feedback, active learning, and an implicit high expectation in performance, for they were not interacting with other students but powerful administrators. This was an important requisite skill; as Bing Gordon of Electronic Arts notes, often one of the greatest challenges for recently hired graduates is working within team structures and interacting with others outside the team (iDMAa conference, 2005). This experience provided an introduction to that process and helped some students make decisions about future goals based on their evaluation of their performance and their degree of comfort.

Project 3. Club Write!, a production for Nashville Public Television Educational Services 
We were fortunate to have an invitation from Nashville Public Television to produce an edition of Club Write!, an instructional program for grade school students distributed by DVD through NPT Educational Services. This gave us the rare opportunity to create a substantive product, and carried with it genuine responsibilities and challenges. We used wireless devices to help with logistics before and during the filming for the DVD. This allowed students at potential filming locations to communicate with each other and gather quickly when conditions at one location were right for shooting. Wireless thus provided what would have been more cumbersome and expensive with older technologies such as two-way radio or phone communications. In particular, the underlying connectivity of the internet eliminated distance as a critical factor.

This project focused on cognitive apprenticeships, where thinking was more important than skill sets. While the students had a textbook-based knowledge of the technology, they quickly learned that this was not enough. Content transfer did not always work as explained in the product literature, and textbook understanding of production requirements such as the lighting of talent, while helpful, did not carry over smoothly into practice, and mobile communications helped facilitate efficient learning. Overlayed on these concerns were the issues involved with using new technologies. There were a substantial number of condition-action pairs to solve (Weigel, 2002) that helped create a complex knowledge ecology, again highlighting active learning, time on task, collaboration, and diverse talents.

Students adopted the same decentralized, relatively anonymous approach as they did with the mock news productions; the details of these forms are given below in Section V.

Project 4. The production of video for mobile devices and the Web.

This course contained the most diverse group of students: television production, recording industry, art, computer science and even history were represented. Thus, this had the most collaborative interplay and the most evidence of critical thinking for example, while they all realized the significance of 'snacks' on mobile devices and the 
Web as ways to integrate into marketing for dominant television productions (e.g., Oprah and Today Show), they also questioned these tactics and discussions evolved regarding the sustainability of such trends and the impact of the internet on marketing. They also moved beyond the real to the ideal, taking advantage of what universities offer: the capacity not only for short-term, task related activity but an environment where we can imagine what can be, what is possible. The striking productions might use the aforementioned 'snacks' but interwove arcs concerning human form and architecture, or the temperospatial shifts that can occur in the framed Web world that would be impossible in the analog realm.

\section{Salient features and outcomes in terms of pedagogy:}

Anonymity can serve as an important aspect of wireless technologies and was deliberately maintained for these projects. Levels of self-esteem vary enormously among students. Anonymity permits an ease in donning power-based positions, unthinkable with some student's standard persona. One student used her facility with Sim City and her avatar to direct a wireless news production. Normally self-effacing to an extreme, her directorial debut was met with enormous success and encouragement from a team that was unaware of her participation. This event fostered her self-confidence in an overt fashion:

This has been awesome to do this kind of work at all. And I did it not just on a grunt level but directing, too. It makes the field more available because I can do the work, now I know it... Hey, Dr. K...I really enjoyed this!

Another shy student began a profit-making avatar design store, again with empowering results. This was a common experience for the many students who found courage within the anonymity to stretch in their attempts. Likewise, students whose appearance usually played a positive part in their social ease and assumption of leadership roles often found less accommodation when these attributes were not evident. Most individuals found the 
use of anonymity valuable for gauging untested abilities and interests, aligning with the best practice of engaging students not otherwise engaged (cte.udel.edu/ccl.html). Further, as with other aspects of the collaborative effort, anonymity's partial safety net helped foment the trust that is so essential for the eventual collaborative work as well as identify new and diverse forms of talent that were previously unrecognized.

One striking difference between these collaborative projects and cooperative television productions involved the development of critical thinking skills and increased creativity evidenced. While the focus of this paper is on the way technology affected the educational experience, it should be noted that other aspects contributed as well, and that would be the case in this circumstance. Some strong effects were due to the interaction of students from various backgrounds. The convergence and collaborative elements appealed to students from art, computer science, history - so it was a diverse mix that interacted and brought new perspectives. Thus the art students helped TV production students think about new perspectives and ideas, and visa versa. Also there was more questioning of assumptions at many levels. For example, the competitive nature of TV production students was often questioned in this new media environment. The interplay meant extraordinary learning opportunities: students involved in computer science would routinely anchor productions in a way that stabilized the more ambitious efforts of art students; art students brought concepts of visual design/color/compostion to the productions; and TV production students brought a sophisticated level of technical knowledge to the process.

One problematic aspect of wireless anonymity emerged, however. Feedback can be brutally honest when it is anonymous; group formations also lend themselves to development of multiple peer assessments that can be harder to handle than individual interchanges. Many students are not prepared for the feedback to be so extensive in level and volume. Interestingly, the foreign students were generally more adept at negotiating this with self-assurance, indicating cultural differences. One best practice, that of studentfaculty contact, takes on unforeseen dimensions here. This is one arena that requires 
careful negotiation and often therapeutic interaction on the part of the instructor, but one that is enormously fruitful given the necessity of this level of engagement as one enters adult relationships and learns to step outside of oneself. Last, the dynamics of feedback mean that best practice of boundary setting pertain to wireless even more than e-mail or discussion groups: rules need to be set limiting offensive language and emotionally destructive interactions, and discussions need to ensue exploring the need for these forms so concepts are negotiated between students and faculty instead of simply applied as another set of faculty commandments.

One aspect of student-faculty contact and prompt feedback, rarely mentioned, involves the tailored interactions required at various times based on the differential skill level exhibited by students. For some, new technology is an opportunity for exploration, for others it is an intimidating challenge. Realistic (i.e., partial and contingent) support is essential given the differential acquisition of skills, as long as it is also constructive and timely (Garrison and Anderson, 2003). With students negotiating and mastering stages at varying rates, it was quickly apparent that judicious and immediate support is essential during stressful periods. And support was not only derived from faculty-student interactions. Again, wireless technology fostered interactions, and on many occasions the more highly skilled students assisted those less skilled, encouraging acquisition of skill sets for the entire group, both for practical reasons and for reasons emanating from the collaborative context.

In terms of the framework for teaching, the mode of instruction was fine-tailored over time to accommodate results. In particular, initial attempts at a convergent approach in instruction, where several teachers from various disciplines worked together in the classroom, proved ineffective. This may have been useful had the students taken courses with the various instructors at consecutive points in their education, but the process generally was unsatisfactory for faculty and students. What worked best was a federalist approach, where one instructor served as groundstone for the class but brought in guest 
speakers at various times. This led to more clarity in instruction and students found it less overwhelming.

Case-base studies proved essential. In particular, cases that challenge norms help develop critical thinking. A good example is the case of Qube and Qube II interactive television projects (Fidler, 1997). Substantial critical thought is needed to discover why the developers did not succeed, and students are empowered to realize that extremely successful businesspeople and researchers were responsible for such large-scale failures. Our culture, like many others, frames failure as akin to tragedy ("the thrill of victory, the agony of defeat"). However, case studies fostered the concept that while success is important, nonetheless growth generally entails some failure as part of the process. This was a significant means of empowering students as they interacted in groups, lessening the fear of failure in front of peers, modifying the stress of immediate feedback, and making high expectations important but less daunting.

Lastly, one comment about the influence of the institution itself on this process. Some universities have various social outlets to enable student interaction, such as the student union, and at these universities the students tend to live on campus and thus have extended periods for interaction. At a largely commuter university like MTSU and many others as well, financial responsibilities preclude such offerings. Yet these interactions are important in collaborative productions. You can not simply be a technophile and create inspired works ${ }^{6}$ : you need input from other perspectives. For many students who work full-time while attending school, that social interaction is spatially and temporally limited. With wireless, however, a form of social network evolved that overcame many of the spatial and temporal limitations of full-time workers. The ability to communicate in a novel way via wireless, both synchronously and asynchronously, at convenient places and times, created a strong social bond, permitting both social and academic

\footnotetext{
${ }^{6}$ A prime example is Rheingold's discussion of DoCoMo (of Nippon Telephone and Telegraph), the only successful $3 \mathrm{G}$ wireless company in Japan. They credit a large part of their success on hiring Mari Matsunaga, whose specialty was launching magazines and was not a technophile. But in concert with technophiles, she helped imbue the product with people-oriented characteristics (Rheingold: 22-23).
} 
exchanges among students that improved critical thinking skills and metacognition, ultimately enriching the digital productions and adding diverse components.

In terms of outcomes, the quality of the projects, which were excellent, and the improvement in general interest, understanding, abilities, and grades were the most rewarding products of this effort:

I always valued my computer. But with wireless it shifted learning to a pretty amazing extent from 'what I know' to 'what I am interested in.' Learning this way was easier and enjoyable...[this] will continue to help me communicate more effectively and make more interesting productions.

This student sent me the above e-mail after the course and grading had been completed. The positive feedback from this approach has been substantial. However, it is also important not to fetishize the technology and its impact. It had its drawbacks in terms of mastering requisite skills, and it worked well but only within the context of a culturally appropriate theoretical framework. That is, the framework was as important as the technology, perhaps more so. And there were some students who did not appreciate the technology or the group learning environment. The chart below indicates general outcomes for the students; responses marked with an asterisk are culled from questionnaires that were administered after final grades were received:

\begin{tabular}{|c|c|c|c|c|}
\hline & \multicolumn{3}{|c|}{ Project \# } & \\
\hline & 1 & 2 & 3 & 4 \\
\hline $\begin{array}{l}\text { *Percent that considered this class a better experience than } \\
\text { standard class }\end{array}$ & $82 \%$ & $78 \%$ & $86 \%$ & $73 \%$ \\
\hline Average increase in grades from prior classes & $13 \%$ & $9 \%$ & $14 \%$ & $13 \%$ \\
\hline *Perceived initial difficulty in using new technology & $45 \%$ & $28 \%$ & $65 \%$ & $33 \%$ \\
\hline $\begin{array}{l}\text { * Self-reported significant increase in understanding of issues } \\
\text { due to wireless applications }\end{array}$ & $92 \%$ & $84 \%$ & $89 \%$ & $73 \%$ \\
\hline
\end{tabular}


This project led to many unexpected outcomes. It was particularly encouraging to witness discussions where the students were engaged deeply in critical thinking about theoretical questions. To give one example where the technology also facilitated the discussion, the students, having read Manovich, discussed how applications like Photoshop and DVD Studio Pro have changed creativity itself. They continued this discussion over wireless when they were not in the classroom, as well as flesh out information to support their arguments. They noted that most applications are menu based, where creativity often meant selection, and they discussed the implications of incorporating mental processes less their own than selected from someone else's sensibilities, debating whether this was truly different from past forms of creativity. They also identified ways this new form of creativity drives media content (DVDs, iconic table of contents, thumbnails) and transforms social practices. In most classes, students learn to imitate the text and can have trouble understanding concepts outside the book's context. But with this learning environment, a willingness to explore was engaged, and deeper thinking emerged: ....as they raced to get stories, we realized that each story had a different perspective. Some people interviewed were close to the event. Some knew the people. Some had time to think about the issues, others were present at the time. Some were officials. Some were involved and others were just normal folks, spectators. We could offer all these perspectives simultaneously and offer a new kind of depth to the news program.

Dialogues like this were far superior to the normative interactions from prior classes. And wireless was integral in this phenomenon. While theoretical concerns formed the bedrock, wireless technology provided structure and process.

Ultimately, the introduction of wireless required an evolution and adaptation to both the technology and the form of interactions required to attend to collaborative work in producing quality digital productions. It offered the deeper, tacit knowledge that comes only through acting on and with phenomena, and it challenged standard approaches and hierarchies. Cultural forms influenced when and how best practices were used and how 
learning was structured. A new form of learning emerged that engaged best practices by the system grounding that wireless necessitates. Using wireless and mobile devices in the creation of digital media forms serves many components of critical thinking as a matter of course: accurate assessment of conditions, the ability to efficiently apply that assessment when developing a plan of action, the technological skill to effect the action, and the ability to evaluate and reassess during the creative process itself. It will be interesting to note the future of these technologies in this educational context, as well as the effects they create in the cultural environment and the ways the cultural environment feed into their metamorphosis. 


\section{References:}

Auman, Ann \& Lillie, Jonathan. "An Evaluation of Team-Teaching Models in a Media Convergence Culture.” Journalism and Mass Communication Educator, Winter 2008: $360-375$.

Bransford, John D., Brown, Ann and Cocking, Rodney, editors. How People Learn:

Brain, Mind, Experience, and School Committee on Developments in the Science of Learning. Commission on Behavioral and Social Sciences and Education of the National Research Council, National Academy Press, 2000.

Chickering, A. W., \& Gamson, Z. F. "Seven principles for good practice in undergraduate education." AAHE Bulletin, 39(7), 1987: 3-7.

Dennis, Everette E., et al. Educator Symposium: “Learning Reconsidered: Education in the Digital Age." Journalism and Mass Communication Educator, Winter 2003, 57/4: 292-420.

Drucker, Peter F. "Beyond the Information Revolution." In Living in the Information Age, Ed. Erik. P. Bucy, Toronto: Wadsworth Group, 2002: 10-17.

Fidler, Roger. Mediamorphosis: Understanding New Media. Thousand Oaks: Pine Forge Press, 1997.

Hall, Edward T. Beyond Culture. New York: Anchor Books, 1978.

Michel Foucault. Discipline and Punish: The Birth of the Prison.

Trans. Alan Sheridan. New York: Vintage, 1977.

Freire, Paulo. Pedagogy of the Oppressed. New York: Continuum, 1993.

Garrison, D. R., and T. Anderson. E-Learning in the $21^{\text {st }}$ Century. London: RoutledgeFalmer, 2003.

Gokhale, Anuradha. “Collaborative Learning Enhances Critical Thinking.” Journal of Technology Education (7), 1, fall 1995.

Hagner, Paul R. "Interesting Practices and Systems in Faculty Engagement and Support.” NLII Focus Session, Seattle, 2000; final report, January 25, 2001.

Jones, Jeffrey. "I Want My Talk TV." In Beyond Prime Time: Television Programming in the Post-Network Era, Ed. Amanda Lotz, Routledge, 2009. 
Kirschner, P. A., Martens, R. L., \& Strijbos, J. W. (2004). CSCL in higher education? A framework for designing multiple collaborative environments. In J. W., Strijbos, P. A., Kirschner, \& R. L., Martens (Eds.), "What we know about CSCL: And implementing it in higher education" (pp. 3-30).

Manovich, Lev. The Language of New Media. Cambridge: MIT Press, 2001.

McCain, Thomas and Leigh Maxwell. "Connected Learning in the Information Age" In Deciphering Cyberspace, Thousand Oaks: Sage Publication, 2003.

Miller, Toby. “Turn Off TV Studies!” Cinema Journal, 45(1), fall 2005: 98-100.s

Negroponte, Nicholas. Being Digital, London: Coronet, 1996.

Nunberg, G and U. Eco (Eds.) The Future of the Book. Berkeley: University of California Press: 1996.

Quentin, Hardy. “The Great Wi-Fi Hope,” Forbes, March 182002.

Resta, Paul \& Thérèse Laferrière. "Technology in Support of Collaborative Learning," Educ Psychol Rev (2007) 19:65-83, 31 January 2007.

Rheingold, Howard. Smart Mobs: The Next Social Revolution. Cambridge: Perseus Publishing, 2002.

Stahl, G. (2004). Building collaborative knowing: Elements of a social theory of CSCL. In J.-W. Strijbos, P.Kirschner, \& R. Martens (Eds.), What we know about CSCL: And implementing it in higher education : 53-86.

Taylor, P. The Texts of Paulo Freire. Buckingham: Open University Press, 1993. von Glasersfeld, Ernst. "Radical Constructivism and Teaching." UMass Scientific Reasoning Research Institute, 2001.

Weigel, Van B. Deep Learning for a Digital Age - Jossey-Bass, S.F. Ca. 2002.

Wenger, Etienne, Richard McDermott, and William M. Snyder. Cultivating Communities of Practice. Boston: Harvard Business School Press, 2002.

Williams, Raymond. Keywords: A Vocabulary of Culture and Society. Rev. Ed., NewYork: Oxford UP, 1983.

Wright, Robin. Nonzero - The Logic of Human Destiny. NY: Vintage Books, 2000. 


\section{Online sources:}

Pew Internet Project, The Internet Goes to College: "How Students are Living in the Future with Today's Technology" http://www.pewinternet.org/reports/toc.asp?Report=71 Ahead of the Curve, video, http://www.cwru.edu/its/no_strings/2003/aotc.htm.

Alexander, Bryan. "Teaching in the Wireless Cloud," The Feature, April 2003, http://www.thefeature.com/article?articleid=35265

Johnson, David W., Roger T. Johnson, and Mary Beth Stanne. "Cooperative Learning Methods: A Meta-Analysis," www.co-operation.org/pages/cl-methods.html

Kageyama, Yuri. http://www.cbsnews.com/stories/2005/03/23/tech/main682569.shtml (2005).

Oblinger, D. G., \& Oblinger, J. L. (Eds.). Educating the Net generation. Washington, DC: Educause http://www.educause.edu/educatingthenetgen (2005).

The Wireless Campus: www.educause.edu/issues/issue.asp?issue=wireless

The Way We Work: http://www.wired.com/wired/archive/11.05/unwired/work.html 